\title{
Structure-mechanical property relations of non-graphitizing pyrolytic carbon synthesized at low temperatures
}

\author{
Itai Y. Stein ${ }^{\mathrm{a}, \mathrm{b}, *}$, Alexander J. Constable ${ }^{\mathrm{c}, \mathrm{d}}$, Naomi Morales-Medina ${ }^{\mathrm{c}, \mathrm{e}}$, Chlöe V. Sackier ${ }^{\mathrm{a}}$, \\ Mackenzie E. Devoe ${ }^{c}$, Hanna M. Vincent ${ }^{\mathrm{c}}$, Brian L. Wardle, ${ }^{\mathrm{a}, * *}$ \\ ${ }^{a}$ Department of Aeronautics and Astronautics, Massachusetts Institute of Technology, Cambridge, Massachusetts \\ 02139, USA \\ ${ }^{b}$ Department of Mechanical Engineering, Massachusetts Institute of Technology, Cambridge, Massachusetts 02139, \\ USA \\ ${ }^{c}$ Department of Materials Science and Engineering, Massachusetts Institute of Technology, Cambridge, \\ Massachusetts 02139, USA \\ ${ }^{d}$ Department of Materials Science and Engineering, The Pennsylvania State University, University Park, \\ Pennsylvania 16801, USA \\ ${ }^{e}$ Department of Physics, University of Puerto Rico, Río Piedras Campus, San Juan, Puerto Rico 00931, USA
}

\begin{abstract}
Polymer derived carbon ceramics are highly desirable for lightweight, high strength, extreme environment material architectures, but their mechanical performance as a function of structure and processing is not currently understood and cannot be predicted. In this study, the mechanical behavior for bulk-scale pyrolytic carbons (PyCs) made via polymer pyrolysis of phenolformaldehyde precursors are established as a function of heat treatment temperature and the resulting average nano- and meso-scale order and disorder via X-ray diffraction, Raman spectroscopy, and Fourier transform infrared spectroscopy. The PyCs exhibit crystallite evolution on both the atomic- and meso-scale for pyrolysis temperatures of $600^{\circ} \mathrm{C}$ to $1000^{\circ} \mathrm{C}$, whereas only atomic-scale crystallite evolution is observed for pyrolysis temperatures of $1000^{\circ} \mathrm{C}$ to $1400^{\circ} \mathrm{C}$. The measured Vickers hardness of the PyCs is observed to scale non-monotonically as a function of the pyrolysis temperature reaching a peak at $\sim 4 \mathrm{GPa}$ for samples prepared at $1000^{\circ} \mathrm{C}$. New modeling results, based on the elastic constants of disordered graphite, indicate that this counter-intuitive Vickers hardness scaling, which is a decades-old open question, originates from the PyC inter-layer shear elastic constant and the crystallite aspect ratio evolution with processing temperature. PyCs studied here are shown to be the lightest super-hard materials, having Vickers hardness-to-density ratios that are comparable to super-hard carbides, oxides, nitrides, and phosphides.
\end{abstract}

\section{Introduction}

The high hardness, low density, thermal stability, and biocompatibility of pyrolytic carbon (PyC) materials have made them promising candidates for ultra-strong super lightweight nanos-

\footnotetext{
*Principal corresponding author

** Corresponding author

Email addresses: iys@alum.mit.edu (Itai Y. Stein), wardle@mit. edu (Brian L. Wardle)
}

Preprint submitted to Carbon

February 28, 2017 
tructured materials, such as nanoarchitected metamaterials [1-10]. Such PyCs can be made at meter-scale through the pyrolysis of polymeric precursors, e.g. polyacrylonitrile, phenol-formaldehyde (phenolic), and many others, through traditional polymer derived ceramics processing [6-10]. However, while previous reports of the mechanical properties of PyCs show that their hardness can either be enhanced or diminished as the pyrolysis temperature $\left(T_{\mathrm{p}}\right)$ is increased [11-14], structuremechanical property relations that are generalizable to PyCs synthesized using a variety of precursor carbon sources and processing techniques are not currently available. Such predictive scaling relations were not previously possible because many studies did not include sufficient information about the structure and morphology of the graphitic crystallites that comprise the PyCs, which hindered the development of structure-mechanical property relations that enable direct comparison of their performance to other PyC systems. Since the effective mechanical properties of PyCs originate from the mechanical behavior of their graphitic crystallites, which strongly depend on atomic and mesoscale order $[15,16]$ incomplete characterization of PyCs overlooks the structural and morphological evolution of the graphitic crystallites, and thereby leads to reports of inexplicable mechanical property scaling as a function of processing. Through extensive characterization of the geometry, bonding character, and chemical structure of the graphitic crystallites that comprise phenolic-derived PyCs, and through modeling of the elastic constants that dominate their mechanical response, this report establishes structure-mechanical property relations that both explain the origin of the non-monotonic scaling of the observed hardness of the PyCs as a function of processing, and enables their performance to be compared to other carbon materials, including previously reported PyCs, and state-of-the-art superhard materials.

Because the effective mechanical properties of PyCs are a function of the nano-/meso-/microstructure, which strongly depends on $T_{\mathrm{p}}$ [17-21], the evolution of structure and mechanical behavior of the PyCs as a function of $T_{\mathrm{p}}$ requires quantification. The original chemical structure of the polymeric precursor can strongly influence the $T_{\mathrm{p}}$ evolution of the resulting PyC [19], and based on early work reported in Ref. 17, PyCs can be characterized by crystallite geometry as either: low density (LD) also known as 'non-graphitizing' PyCs; and high density (HD) also known as 'graphitizing' PyCs. Clearly nano- and meso-scale porosity also contribute to the performance of these materials, but the LD and HD classification along with density is found to be the most useful description. The main difference between LD and HD PyCs is that, although they both form graphitic crystallites characterized by their size size $\left(L_{\mathrm{a}}\right)$, from the (100) and (110) 3D lattice planes (i.e. via the [100] and [110] Miller indices also known as $h k \ell$ ) [20-25], and thickness $\left(L_{c}\right)$, from the (002) lattice plane (i.e. via the [002] $h k \ell$ ) [20-25], the graphitic crystallites in HD PyCs have a narrower orientation distribution, i.e. texture, and exhibit significant $L_{\mathrm{c}}$ growth at $T_{\mathrm{p}} \lesssim 2000^{\circ} \mathrm{C}$, i.e. the crystallites in HD PyCs have a lower aspect ratio characterized by $L_{\mathrm{a}} / L_{\mathrm{c}}$ than the crystallites that comprise LD PyCs [17]. See Fig. 1 for an illustration of the nanostructure of LD and HD PyCs along with the relevant graphitic crystallite geometries quantified via $L_{\mathrm{a}}$ and $L_{\mathrm{c}}$ that originate from the (100) and (002) lattice planes. These differences that distinguish HD PyCs from LD PyCs still hold at $T_{\mathrm{p}} \gtrsim 3000^{\circ} \mathrm{C}$ [17], and have a strong impact on how graphitic crystallites of $\mathrm{HD}$ and LD PyCs grow when processed at both $T_{\mathrm{p}} \gtrsim 1500^{\circ} \mathrm{C}$, which only specialized equipment such as the ones designed for carbon fiber synthesis can achieve, and $T_{\mathrm{p}} \lesssim 1500^{\circ} \mathrm{C}$ that many commercially available laboratory furnaces can achieve.

Since simulation indicates that processing at elevated temperatures enables the migration of 




Figure 1: Previously reported structure-mechanical data relations of pyrolytic carbon (PyC). (a) Sketch of exemplary LD and HD packing structures of graphitic crystallites in PyCs where an 15\% increase in density from LD to HD is typical, and illustration of representative crystallite size $\left(L_{\mathrm{a}}\right)$ and thickness $\left(L_{\mathrm{c}}\right)$ that are used to quantify the size and geometry of the crystallites that comprise the PyCs. The relationship of $L_{\mathrm{a}}$ and $L_{\mathrm{c}}$ with the [100] and [001] $h k \ell$ lattice directions that are orthogonal to the (100) and (002) lattice planes is also indicated. Note: for the 3-layer crystallite illustrated here, $L_{\mathrm{c}}$ is twice the inter-layer separation by convention. (b) Previously reported scaling of PyC Vickers hardness $\left(H_{\mathrm{V}}\right)$ for $\operatorname{LD}(\bullet$, and $\boldsymbol{\nabla})$ and $\mathrm{HD}(\boldsymbol{\nabla})$ PyCs as a function of $L_{\mathrm{a}}$ and $L_{\mathrm{c}}$ showing the wide spread and lack of a trend $[13,14]$.

defects in the graphitic crystallites that comprise the PyCs [26], which could strongly influence strength and toughness of graphitic systems [27-31], evaluation of the mechanical behavior of the PyCs as a function of $T_{\mathrm{p}}$ is necessary. Although nanoindentation is one of the most prevalent techniques for evaluation of the mechanical properties of materials, this technique is very sensitive to minute changes in microstructure $[32,33]$, and would likely yield inconclusive results in the highly porous PyCs studied here. The Vickers microhardness test, which has a larger indentation area (and a wider range of operating loads) than nanoindentation, can be successfully used to quantify the mechanical properties of a variety of materials, i.e. metals, ceramics, and polymers, independent of their Vickers hardness $\left(H_{\mathrm{V}}\right)$, yields the most useful and comparable mechanical characterization of PyCs and other carbon materials [34]. Recent studies of the mechanical behavior of defective graphene indicates that the presence of lattice vacancies leads to reduced resistance to deformation $[31,35,36]$, and that processing that evolves the microstructure of the PyCs away from amorphous carbon and towards nanocrystalline graphite, such as higher $T_{\mathrm{p}}$, will lead to significantly higher elastic moduli and breaking loads [31]. However, previous work on LD and HD PyCs processed at $T_{\mathrm{p}}$ up to $2000^{\circ} \mathrm{C}$ showed that the mechanical properties of the PyC can either 
be enhanced or diminished depending on the $T_{\mathrm{p}}[11,13,14]$. Based on the data presented in these previous studies, the non-monotonic scaling of the mechanical properties of these PyCs as a function of $T_{\mathrm{p}}$ might originate from changes in $L_{\mathrm{a}}$ and $L_{\mathrm{c}}$, but the large spread and lack of obvious trend in the reported data has prevented the development of a unified scaling relation that relates the crystallite structure and morphology to the observed $H_{\mathrm{V}}$ results. See Fig. 1 for the previously reported $H_{\mathrm{V}}$ results for $\mathrm{LD}$ and $\mathrm{HD}$ PyCs as a function of $L_{\mathrm{a}}$ and $L_{\mathrm{c}}$. Additionally, conflicting simulation results reported in the literature for size effects in graphene flakes have not clarified the observed experimental $H_{\mathrm{V}}$ trends for PyCs [37-39]. This confusion originates from both the incomplete characterization of the morphology and structure of the graphitic crystallites that comprise the PyCs and the lack of understanding of the physical mechanism that dominates the PyC mechanical behavior, since the elastic constants that govern deformation of layered carbon materials can vary by orders of magnitude depending on the structure and morphology of the graphitic crystallites [15].

The most widespread techniques for topological, morphological, and structural characterization of nano-carbon materials, including PyCs, are scanning (SEM) and transmission (TEM) electron microscopy [40-43], which were previously utilized to visualize and qualitatively investigate the atomic and meso-scale evolution of PyCs during pyrolysis [14, 44-47]. However, these techniques are limited to sampling very small volumes [21, 40], making them less well-suited for quantitative structural analysis of the as-synthesized bulk volume of PyCs studied here $(\propto 0.1$ $\mathrm{cm}^{3}$ ) than large sampled volume techniques used here that include X-ray diffraction (XRD), Raman spectroscopy, and Fourier transform infrared (FTIR) spectroscopy. In this report, the in-depth morphological, structural, and chemical information collected from the large sampled volume $\mathrm{XRD}$, Raman spectroscopy, and FTIR spectroscopy characterization of the PyCs is used to develop a scaling relation that couples $L_{\mathrm{a}}, L_{\mathrm{c}}$, and inter-layer separation $\left(d_{002}\right)$ to the $H_{\mathrm{V}}$ evolution as a function of $T_{\mathrm{p}}$ observed here and in previous work that dates back more than 40 years.

\section{Methods}

\subsection{Synthesis and Processing Techniques}

Pure phenol-formaldehyde samples (Durite SC-1008, Momentive Specialty Chemicals, Inc.) were prepared by first pouring the de-gassed resin into a round aluminium molds, and then curing at $80^{\circ} \mathrm{C}$ for $6 \mathrm{hr}$ [48-50]. The samples were then heat treated to transform the phenolic resin into PyC, which could enable the native defects to migrate and annihilate [26]. Pyrolysis was performed using a commercial hot wall tube furnace (STT-1600, from SentroTech Corp.) with a 3.5 in inner diameter $\mathrm{SiC}$ tube in an $\mathrm{Ar}$ environment at a ramp rate of $4^{\circ} \mathrm{C} / \mathrm{min}$ (furnace maximum) at the following $T_{\mathrm{p}}$ and hold times ( $\left.t_{\text {hold }}\right)$ of $t_{\text {hold }}=30 \mathrm{~min}$ : $600^{\circ} \mathrm{C}, 800^{\circ} \mathrm{C}, 1000^{\circ} \mathrm{C}, 1200^{\circ} \mathrm{C}$, and $1400^{\circ} \mathrm{C}$. An alumina boat was used to ensure that the prepared PyC samples exhibited minimal curvature post-pyrolysis.

\subsubsection{XRD Analysis}

To calculate the average effective $L_{\mathrm{a}}$ and $L_{\mathrm{c}}$ of the graphitic crystallites that comprise the PyCs, the (100) and (002) peaks of the XRD pattern are used in conjunction with the Scherrer equations 
as follows [22-25]:

$$
\begin{aligned}
& L_{\mathrm{c}}=\frac{0.89 \lambda_{\mathrm{xrd}}}{\beta_{002} \cos \left(\theta_{002}\right)} \\
& L_{\mathrm{a}}=\frac{1.84 \lambda_{\mathrm{xrd}}}{\beta_{100} \cos \left(\theta_{100}\right)}
\end{aligned}
$$

where $\lambda_{\text {xrd }}$ is the wavelength of the incident X-ray radiation, $\beta_{002}$ and $\beta_{100}$ are the full width at half maximum of the (002) and (100) peaks, and $\theta_{002}$ and $\theta_{100}$ are the positions of the (002) and (100) peaks. The peak position and full width at half maximum of the (110), $\theta_{110}$ and $\beta_{110}$, can also be used in Eq. 1a (i.e. instead of $\theta_{100}$ and $\beta_{100}$, respectively) to yield an independent and supplemental approximation of $L_{\mathrm{a}}$, but the (110) peak may not appear in the XRD pattern until the PyC has gone through graphitization at very high temperature $\left(T_{\mathrm{p}}>3000^{\circ} \mathrm{C}\right)[51]$, and may therefore be unavailable for PyCs synthesized at low $T_{\mathrm{p}}$. Another geometry parameter that can be utilized to analyze the structure and morphology of the graphitic crystallites is the (002) inter-layer separation $\left(d_{002}\right)$ that is determined using the Bragg's law as follows:

$$
n_{\mathrm{xrd}} \lambda_{\mathrm{xrd}}=2 d_{002} \sin \left(\theta_{002}\right)
$$

where $n_{\mathrm{xrd}}$ is an integer that corresponds to the number of (002) layers the incident radiation traveled before being reflected ( $\rightarrow n_{\mathrm{xrd}}=1$ is normally assumed).

The PANalytical X'Pert Pro was used to analyze PyC samples post-pyrolysis. $\mathrm{Cu} \mathrm{K}_{\alpha}$ radiation was passed through a $2^{\circ}$ anti-scattering slit with a 0.04 rad Soller slit in $X^{\prime}$ celerator mode. The XRD experiment was performed at $45 \mathrm{kV}$ and $40 \mathrm{~mA}$ with a scanning step interval of $0.02^{\circ}$ ( $\left.2 \theta_{\mathrm{xrd}}\right)$. $\mathrm{LaB}_{6}$ was used as the standard material for all measurements. The approximate values of $L_{\mathrm{a}}$ (via Eq. 1a), $L_{\mathrm{c}}$ (via Eq. 1b), and $d_{002}$ (via Eq. 2) are presented in Table S1 (Supplementary Materials).

\subsubsection{Raman Spectroscopy Analysis}

Raman spectra were collected using a LabRam HR800 Raman microscope (Horiba Jobin Yvon) with $532 \mathrm{~nm}(2.33 \mathrm{eV})$ laser excitation through a $50 \times$ objective (N.A. 0.75). Several spots on each PyC sample were studied to ensure that representative data was used when calculating the $I_{\mathrm{D}} / I_{\mathrm{G}}$ and $A_{\mathrm{D}} / A_{\mathrm{G}}$. To facilitate the analysis of the defect information provided by Raman spectroscopy, the Raman spectra were fit using two Lorentzian distributions corresponding to the graphitic D-band (centered at $\omega_{\mathrm{D}} \sim 1350 \mathrm{~cm}^{-1}$ ) and a-C G-band (centered at $\omega_{\mathrm{G}, \mathrm{a}-\mathrm{C}} \sim 1500$ $\mathrm{cm}^{-1}$ ) [21, 52, 53], and Breit-Wigner-Fano distribution that corresponds to the graphitic G-band (centered at $\omega_{\mathrm{G}} \sim 1590 \mathrm{~cm}^{-1}$ ) [54-56]. The fitting expression detailed in Section S1 (Supplementary Materials) yielded very good agreement $\left(\mathbb{R}^{2}>0.99\right)$ with the experimental Raman spectra of PyCs at $1000 \mathrm{~cm}^{-1} \leq \omega \leq 1800 \mathrm{~cm}^{-1}$, and $I_{\mathrm{D}} / I_{\mathrm{G}}$ was evaluated simply using the $I_{\mathrm{D}}$ and $I_{\mathrm{G}}$ from the Lorentzian and BWF fits of the D- and G-bands, while $A_{\mathrm{D}} / A_{\mathrm{G}}$ was evaluated using the areas of the Lorentzian and BWF fits of the D- and G-bands ( $A_{\mathrm{D}}$ and $A_{\mathrm{G}}$, respectively). See Section $\mathrm{S} 1$ (Supplementary Materials) for details.

\subsubsection{FTIR Analysis}

FTIR spectroscopy was performed using a FTIR6700 Fourier Transform Infrared Spectrometer (Thermo Fisher Scientific, Inc.), and the chemical structure was analyzed using the OMNIC 
software (Thermo Fisher Scientific, Inc.). The attenuated total reflection mode technique was used to study the chemistry of a cured phenolic resin baseline, and the $\mathrm{KBr}$ pellet method was employed in transmission mode. All FTIR signal was transformed to absorbance mode during the analysis. An average of 32 scans with a resolution of $8 \mathrm{~cm}^{-1}$ were taken for each sample, and 3 samples were tested at each $T_{\mathrm{p}}$.

\subsubsection{Experimental Vickers Microhardness Evaluation}

Vickers microhardness testing was done using a LECO LM Series Microhardness Tester (LECO Corp.) by placing each mounted sample under a $50 \times$ objective magnification lens. Indentation was performed following ASTM standard C1327-08 [57] by applying $500 \mathrm{gf}$ ( 4.9 N, to avoid formation of surface cracks) at each spot for $10 \mathrm{~s}$, and $H_{\mathrm{V}}$ was approximated at each $T_{\mathrm{p}}$ by indenting 5 samples at least 10 times $\left(\rightarrow>50\right.$ measurements per $\left.T_{\mathrm{p}}\right) . H_{\mathrm{V}}$ as a function of $T_{\mathrm{p}}$, along with the corresponding density of (dried) PyCs, can be found in Table S3 (Supplementary Materials). For hard ceramics and many other materials [58-60], particularly the types studied here [61], there is a linear relationship between measured Vickers hardness and stiffness. This is discussed in more detail in Section 3.5.

\section{Results and Discussion}

\subsection{Graphitic Crystallite Geometry Evolution}

A common approach to approximate the crystallite geometry in carbon materials is through the effective $L_{\mathrm{a}}, L_{\mathrm{c}}$, and $d_{002}$ that are computed from their X-ray diffraction (XRD) patterns (details can be found in the Experimental Section) [23-25]. See Fig. 2 for the XRD patterns, and the evaluated $L_{\mathrm{a}}, L_{\mathrm{c}}$, and $d_{002}$ as a function of $T_{\mathrm{p}}$ are summarized in Table S1 (Supplementary Materials). As shown in Fig. 2a, the diffraction patterns (smoothed using a 32-point moving average) of phenolic resin transforming into $\mathrm{PyC}$ exhibit two main peaks of interest: the first is observed at $18^{\circ} \lesssim 2 \theta \lesssim$ $22^{\circ}$ and belongs to the (002) plane [62,63]; and the second is observed at $2 \theta \approx 43^{\circ}$ and belongs to the $(100)$ plane $[62,63]$. The translation of the (002) peak and large changes in intensity of the (100) peak (relative to the (002) peak) are indicative of a decrease in average crystallite curvature (i.e. fluctuation of the $d_{002}$ ) and a turbostratic stacking order [63] Turbostratic stacking order is further supported by the evolution of $d_{002}$ as a function of $T_{\mathrm{p}}$, as shown in Table S1 (Supplementary Materials) and Fig. 2b, which indicate that although $d_{002}$ decreases with $T_{\mathrm{p}}, d_{002}$ plateaus at $d_{002} \sim 0.37 \mathrm{~nm}$ and a $d_{002} \lesssim 0.34 \mathrm{~nm}$ value indicative of Bernal (i.e. ABAB) stacked graphite is not observed. Additionally, the (002) peak may also be related to both annihilation of native defects and an increase in $L_{\mathrm{c}}$ of the graphitic crystallites [63]. These results indicate that while higher $T_{\mathrm{p}}$ leads to lower crystallite curvature and disorder, the crystallites are still not truly graphitic in nature, since the $(002)$ peak is at $2 \theta<26.5^{\circ}((002)$ peak position for graphite), and that the glassy crystallite arrangement that is expected for phenol-formaldehyde undergoing pyrolysis likely holds $[64,65]$. Using the (002) and (100) peaks, the geometry of the graphitic crystallites that comprise the PyCs can be studied further.

As Table S1 (Supplementary Materials) and Fig. 2b illustrate, both $L_{\mathrm{a}}$ and $L_{\mathrm{c}}$ increase with increasing $T_{\mathrm{p}}$ up to $T_{\mathrm{p}} \sim 1000^{\circ} \mathrm{C}$, and that $L_{\mathrm{a}}$ plateaus at $L_{\mathrm{a}} \sim 6.3 \mathrm{~nm}$ for $T_{\mathrm{p}}>1000^{\circ} \mathrm{C}$ while $L_{\mathrm{c}}$ continues increasing past $L_{\mathrm{c}} \sim 2 \mathrm{~nm}$. These values of $L_{\mathrm{a}}$ and $L_{\mathrm{c}}$ indicate that the PyCs studied 

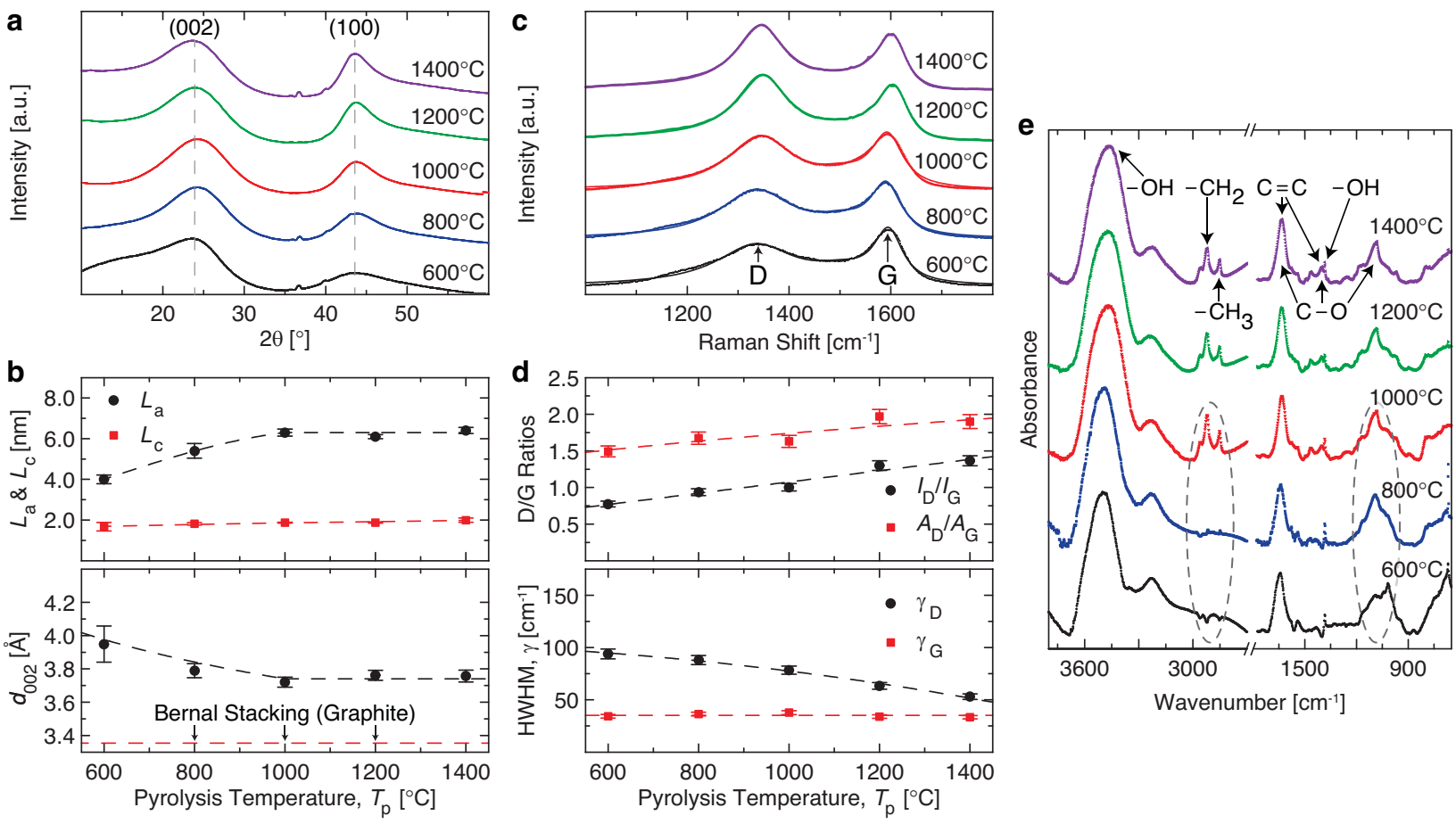

Figure 2: Pyrolytic carbon (PyC) structure and morphology as a function of pyrolysis temperature $\left(T_{\mathrm{p}}\right)$. (a) Representative X-ray diffraction (XRD) patterns showing the evolution of the (002) and (100) peaks. (b) Graphitic crystallite size $\left(L_{\mathrm{a}}\right)$, thickness $\left(L_{\mathrm{c}}\right)$, and (002) inter-layer spacing $\left(d_{002}\right)$ scaling with processing. (c) Raman spectra showing the evolution of the D- and G-bands as $T_{\mathrm{p}}$ increases. (d) Evaluated intensity $\left(I_{\mathrm{D}} / I_{\mathrm{G}}\right)$ and area $\left(A_{\mathrm{D}} / A_{\mathrm{G}}\right)$ ratios, and half width half maximums ( $\gamma_{\mathrm{D}}$ and $\gamma_{\mathrm{G}}$ ), respectively) of the D- and G-bands as a function of processing. (e) Fourier transform infrared (FTIR) spectroscopy pattern changes revealing the chemical structure of the PyCs.

here are non-graphitizing LD PyCs $\left(\rightarrow L_{\mathrm{a}} / L_{\mathrm{c}}=2-3\right)$ that should assume an 'open structure' [14, 17]. Phenol-formaldehyde resins typically produce glassy PyCs [65], and will therefore not yield graphite even after processing in $T_{\mathrm{p}}>2000^{\circ} \mathrm{C}$ [66].

\subsection{Bonding Character Evolution}

Raman spectroscopy is a widely used non-destructive technique for studying defects and disorder in carbon materials [54, 67-69], and representative Raman spectra for PyCs undergoing pyrolysis at $600^{\circ} \mathrm{C} \leq T_{\mathrm{p}} \leq 1400^{\circ} \mathrm{C}$ along with their three-band fitting functions (see Section S1, Supplementary Materials), are presented in Fig. 2c. As Fig. 2c shows, the main qualitative evolution of the Raman spectra is that the D-band, which is normally found at $\sim 1335-1350 \mathrm{~cm}^{-1}$ and is representative of defects/disorder in the (002) plane [54, 67-71], is increasing in intensity, while the G-band, which usually found at $\sim 1580-1600 \mathrm{~cm}^{-1}$ and corresponds to the in-plane $\mathrm{sp}^{2}$ bond stretching [54, 67-71], is unchanged. This is confirmed in Fig. 2d, where the intensity $\left(I_{\mathrm{D}} / I_{\mathrm{G}}\right)$ and area $\left(A_{\mathrm{D}} / A_{\mathrm{G}}\right)$ ratios of the $\mathrm{D}$ - and G-bands, which are a common way to discern whether one material/sample is more or less graphitic than another [54, 67, 72, 73], are presented as a function of $T_{\mathrm{p}}$. As Fig. $2 \mathrm{~d}$ illustrates, $I_{\mathrm{D}} / I_{\mathrm{G}}$ and $A_{\mathrm{D}} / A_{\mathrm{G}}$ both increase as a function of $T_{\mathrm{p}}$, which is attributed to thermally-activated defect formation. Although Raman cannot distinguish what kind of 
defects are forming, the XRD results indicate that the graphitic crystallites that comprise the PyCs grow until $T_{\mathrm{p}} \sim 1000^{\circ} \mathrm{C}$, at which point $L_{\mathrm{a}}$ and $L_{\mathrm{c}}$ are either constant or grow very slowly. This means that as $T_{\mathrm{p}}$ increases until $T_{\mathrm{p}} \sim 1000^{\circ} \mathrm{C}$, the graphitic crystallites are both forming grain boundaries within the (001) family of planes (consistent with a growing $L_{\mathrm{a}}$ ) and stacking additional (disordered) graphene-like layers on top of the (001) basal plane (consistent with a growing $L_{\mathrm{c}}$ ), while at $T_{\mathrm{p}} \sim 1400^{\circ} \mathrm{C}$ the graphitic crystallites are mainly growing in the $L_{\mathrm{c}}$ direction that indicates a possible plateau in $I_{\mathrm{D}} / I_{\mathrm{G}}$ and $A_{\mathrm{D}} / A_{\mathrm{G}}$. This type of behavior is consistent with stage 2 in the three-stage amorphization trajectory originally proposed in Ref. 54, and further explored for defective graphene in Ref. 74 , but $\gamma_{\mathrm{D}}$ and $\gamma_{\mathrm{G}}$ must be evaluated to quantify the amorphization stage that is most relevant here (see Fig. 2d). As Fig. $2 d$ indicates, $\gamma_{D}$ decreases as a function of $T_{\mathrm{p}}$ from $\gamma_{\mathrm{D}} \sim 90$ to $50 \mathrm{~cm}^{-1}$, while $\gamma_{\mathrm{G}}$ remains constant to within the experimental uncertainty at $\gamma_{\mathrm{G}} \sim 35 \mathrm{~cm}^{-1}$. This value and scaling of $\gamma_{\mathrm{G}}$ is in very good agreement with a recent study on PyCs that were in stage 2 of the amorphization trajectory (since $\gamma_{\mathrm{G}}<15 \mathrm{~cm}^{-1}$ for stage 1) [74], where $\gamma_{\mathrm{G}} \sim 40 \mathrm{~cm}^{-1}$ was observed for $4 \mathrm{~nm} \lesssim L_{\mathrm{a}} \lesssim 6 \mathrm{~nm}$, and where $\gamma_{\mathrm{D}} / \gamma_{\mathrm{G}}$ was seen to decrease from $\gamma_{\mathrm{D}} / \gamma_{\mathrm{G}} \sim 2$ to 1.4 (the range is $\gamma_{\mathrm{D}} / \gamma_{\mathrm{G}} \sim 2.5$ to 1.4 here) in the same $L_{\mathrm{a}}$ regime [56]. Therefore we know that the PyCs studied herein are clearly 'non-graphitizing' and within stage 2 of the graphitization trajectory, i.e. their structure is evolving from amorphous carbon-like toward nano-crystalline graphene/graphite-like [54], which means that the elastic constants of disordered/turbostratic graphite are the ones governing their mechanical behavior as discussed later.

\subsection{Chemical Structure Evolution}

Fourier transform infrared (FTIR) spectroscopy is a versatile and powerful analysis method for evaluating the chemical structure of carbon materials [75], and representative FTIR patterns of the PyCs can be found in Fig. 2e. As Fig. 2e demonstrates, there is evidence of-OH stretching, which is characteristic of thermoset resin such as phenol-formaldehyde [76] and is represented by the $\sim 3455 \mathrm{~cm}^{-1}$ band [76, 77]. The bands at $\sim 2920 \mathrm{~cm}^{-1}$ and $\sim 2851 \mathrm{~cm}^{-1}$ correspond to $\mathrm{sp}^{2}$ $\left(-\mathrm{CH}_{2}\right)$ and $\mathrm{sp}^{3}\left(-\mathrm{CH}_{3}\right)$ functional groups[77], and their evolution as $T_{\mathrm{p}}$ increases is consistent with the XRD results (see Fig. 2b) since such functional groups would most likely be affected by changes in the aspect ratio of the crystallites that comprise the PyCs. Also, Fig. 2e illustrates the presence of $\mathrm{C}=\mathrm{C}$ stretching in the aromatic rings that comprise the graphitic crystallites, which is represented by the $\sim 1636 \mathrm{~cm}^{-1}$ peak [77, 78]. The broadening of the $\sim 1636 \mathrm{~cm}^{-1}$ band could also be attributed to $\mathrm{C}-\mathrm{O}$ in the benzophenone groups [11]. Having both peaks around $\sim 1374$ $\mathrm{cm}^{-1}$ and $\sim 1636 \mathrm{~cm}^{-1}$ could also indicate the presence of $\mathrm{C}-\mathrm{O}$ stretching originating from carboxyl groups [78]. Since C-O groups are most likely present either between the layers of the graphitic crystallites, or on their edges, the evolution of the band at $\sim 1060 \mathrm{~cm}^{-1}$, which is also likely a result of $\mathrm{C}-\mathrm{O}$ stretching $[75,77,78]$, as $T_{\mathrm{p}}$ increases is consistent with the crystallite size evolution observed by XRD (see Fig. 2b). The changes in the aromatic parts $\left(675-900 \mathrm{~cm}^{-1}\right)$ as a function of $T_{\mathrm{p}}$ can be traced back to the proportion of $-\mathrm{CH}$ groups present in the condensed aromatic structures, and those found in the phenyl ring [76]. This indicates that the changes are related to the interaction between the phenolic groups, which results in further cross-linking via ether bridges [76]. These FTIR results indicate that as $T_{\mathrm{p}}$ increases, the most significant chemical structure changes occur between the graphitic layers and on the edges of the crystallites that comprise the PyCs, and in the next section a scaling relation is developed to relate all these structural 
changes (see Fig. 2e) to the mechanical properties of the PyCs.

\subsection{Theoretical Framework for Hardness Scaling with Crystallite Geometry}

To model the mechanical behavior of PyCs, the relevant deformation modes that would be activated during indentation must first be discussed. As analyzed in detailed in a previous study [15], graphitic carbons have very anisotropic elastic constants for in-plane extension $\left(C_{11}\right)$, out-of-plane extension $\left(C_{33}\right)$, and inter-layer shear $\left(C_{44}\right)$. See Fig. 3a for an illustration of mechanics that govern $C_{11}, C_{33}$, and $C_{44}$, and Table S2 (Supplementary Materials) for a summary of their reported experimental and theoretical values. As Table S2 (Supplementary Materials) demonstrates, $C_{11} \gg C_{33} \gg C_{44}$, especially for turbostratic carbons where $C_{11}>3000 \times C_{44}$ and $C_{33}>100 \times C_{44}$. This indicates that the inter-layer shear deformation mode, governed by $C_{44}$, will dominate the mechanical behavior of the graphitic crystallites ( $>90 \%$ effective compliance contribution) that comprise the PyC matrix, while the deformation modes governed by $C_{11}$ and $C_{33}$ will contribute $<10 \%$ to the effective compliance, especially when the crystallite orientation angle $\theta_{\text {oa }} \sim 45^{\circ}$ (i.e. isotropic crystallite orientation). The assumption that $\theta_{\mathrm{oa}} \sim 45^{\circ}$ is further supported by the low PyC apparent density $\left(<1.2 \mathrm{~g} / \mathrm{cm}^{3}\right.$, see Table S3 in the Supplementary Materials), which was previously shown to correlate with a low degree of graphitic crystallite texture/preferrential orientation in PyCs [14, 44, 45]. Additionally, Table S2 (Supplementary Materials) illustrates that $C_{44}$ is strongly dependent on the crystallite morphology, since Bernal stacked (ABAB) graphite has a $10 \times$ larger $C_{44}$ than turbostratic graphite. This means that knowledge of $d_{002}$ is essential, since $d_{002} \approx 0.34 \mathrm{~nm}$ is normally ascribed to ABAB graphite $\left(C_{44} \sim 4.5 \mathrm{GPa}\right)[15,79,80]$, while $d_{002}>0.35 \mathrm{~nm}$ is usually classified as turbostratic graphite/carbon $\left(C_{44} \sim 0.35 \mathrm{GPa}\right)$ [15, 81]. Also, since it was recently shown that the presence of inter-layer bonds/functional groups can increase the pulling force/stress needed for inter-layer shear $\left(\propto C_{44}\right)$ by $>3 \times$ in graphene, graphene oxide, and CNTs [82, 83], meaning that the crystallite area $\left(\propto L_{\mathrm{a}}^{2}\right)$, which correlates the number of inter-layer bonds in a graphitic crystallite to the defect density, should also scale the effective Vickers hardness measured via indentation. Finally, since the inter-layer shear strain and energy of the lowest available shear mode, as extensively explored in recent studies of the layer shear modes/C-band evolution in Raman spectra of multi-layered 2D materials [80, 84-86], both scale as a function of $L_{c}$ (i.e., the number of layers of the crystallites, since $d_{002}$ does not vary by more than $10 \%$ ), a factor of $L_{c}^{2}$ accounting for both contributions should also scale the effective Vickers hardness measured via indentation. The following general and reduced forms of the scaling of the theoretical indentation Vickers hardness $\left(H_{\mathrm{V}, \text { th }}\right)$ as a function of $L_{a}, L_{c}, C_{11}, C_{33}, C_{44}$, and $\theta_{\mathrm{oa}}$ are proposed:

$$
\begin{gathered}
H_{\mathrm{V}, \mathrm{th}} \propto\left(\frac{\cos \left(\theta_{\mathrm{oa}}\right)}{C_{11}}+\frac{\sin \left(\theta_{\mathrm{oa}}\right)}{C_{33}}+\frac{\sin \left(2 \theta_{\mathrm{oa}}\right)}{C_{44}}\left(\frac{L_{c}}{L_{a}}\right)^{2}\right)^{-1} \\
\hookrightarrow H_{\mathrm{V}, \mathrm{th}} \propto C_{44}\left(\frac{L_{a}}{L_{c}}\right)^{2}
\end{gathered}
$$

where the approximation of Eq. 3a made in Eq. $3 \mathrm{~b}$ is reasonable for $10^{\circ} \leq \theta_{\mathrm{oa}} \leq 80^{\circ}$, and fails at $10^{\circ}>\theta_{\text {oa }}$, where the $C_{11}$ in-plane deformation dominates, and at $80^{\circ}<\theta_{\text {oa }}$, where the $C_{33}$ out- 
of-plane deformation dominates. Analysis of the $H_{\mathrm{V} \text {,th }}$ predictions from Eq. $3 \mathrm{~b}$ are discussed and compared to experimental $H_{\mathrm{V}}$ values in the next section.

\subsection{Mechanical Behavior Scaling}

The scaling of $H_{\mathrm{V}}$ as a function of $T_{\mathrm{p}}$ is presented in Fig. 3b (and Table S3, Supplementary Materials). As Fig. 3b demonstrates, $H_{\mathrm{V}}$ for the PyCs increases from $H_{\mathrm{V}} \sim 2.1 \mathrm{GPa}$ at $T_{\mathrm{p}}=$ $600^{\circ} \mathrm{C}$ to $H_{\mathrm{V}} \sim 4.0 \mathrm{GPa}$ at $T_{\mathrm{p}}=1000^{\circ} \mathrm{C}$, and then subsequently decreases to $H_{\mathrm{V}} \sim 3.5 \mathrm{GPa}$ at $T_{\mathrm{p}}=1400^{\circ} \mathrm{C}$. See Table S3 (Supplementary Materials) for the experimentally and theoretically determined $H_{\mathrm{V}}$ and PyC density $\left(\rho_{\text {pyc }}\right)$ as a function of $T_{\mathrm{p}}$. While this non-monotonic scaling of $H_{\mathrm{V}}$ as a function of $T_{\mathrm{p}}$ may seem counterintuitive, Eq. $3 \mathrm{~b}$ in combination with $L_{\mathrm{a}}, L_{\mathrm{c}}$, and $d_{002}$ is able to explain this behavior. To do so, an approximation for $C_{44}$ must first be established, and since XRD indicates that the PyCs studied here exhibit turbostratic stacking, with $d_{002}>0.35 \mathrm{~nm}$ (see Fig. 2b), $C_{44}$ can be estimated with $C_{44} \sim 0.35 \mathrm{GPa}$. Next, the evolution of $L_{\mathrm{a}} / L_{\mathrm{c}}$ as a function of $T_{\mathrm{p}}$ needs to be examined. Using the values for $L_{\mathrm{a}}$ and $L_{\mathrm{c}}$ from XRD, $L_{\mathrm{a}} / L_{\mathrm{c}}$ is seen to increase from $L_{\mathrm{a}} / L_{\mathrm{c}} \sim 2.4$ at $T_{\mathrm{p}}=600^{\circ} \mathrm{C}$ to $L_{\mathrm{a}} / L_{\mathrm{c}} \sim 3.4$ at $T_{\mathrm{p}}=1000^{\circ} \mathrm{C}$, and then subsequently decreases to $L_{\mathrm{a}} / L_{\mathrm{c}} \sim 3.2$ at $T_{\mathrm{p}}=1400^{\circ} \mathrm{C}$. Using the scaling relation proposed in Eq. $3 \mathrm{~b}$ and $C_{44} \sim 0.35 \mathrm{GPa}$, the theoretical $H_{\mathrm{V}}$ evolution is: $H_{\mathrm{V}}$ increases from $H_{\mathrm{V}} \sim 2.0 \mathrm{GPa}$ at $T_{\mathrm{p}}=600^{\circ} \mathrm{C}$ to $H_{\mathrm{V}} \sim 3.9 \mathrm{GPa}$ at $T_{\mathrm{p}}=1000^{\circ} \mathrm{C}$, and then subsequently decreases to $H_{\mathrm{V}} \sim 3.6 \mathrm{GPa}$ at $T_{\mathrm{p}}=1400^{\circ} \mathrm{C}$. See Table S3 (Supplementary Materials) for details. This theoretical evolution of $H_{\mathrm{V}}$ is in very good agreement with the experimental observations here.

This analysis can be extended to $H_{\mathrm{V}}$ results previously reported for PyCs in Refs. 13 and 14. In Ref. 13, there were many samples studied, but only 4 different $T_{\mathrm{p}}$. This means that the data from Ref. 13 is representative data from multiple samples. Additionally, since the results from Ref. 13 that are included in Fig. $3 \mathrm{~b}$ originate from samples that exhibit $d_{002} \gtrsim 0.35 \mathrm{~nm}, C_{44}$ for this data set can also be taken as $C_{44} \sim 0.35 \mathrm{GPa}$ for turbostratic carbon [15]. As Fig. 3b demonstrates (error bars and dashed lines are guides to the eye and correspond to $\pm 5 \%$ uncertainty in the data and Eq. $3 \mathrm{~b}$ predictions, respectively), Eq. $3 \mathrm{~b}$ in combination with the reported values of $L_{\mathrm{a}}$ and $L_{\mathrm{c}}$ lead to a predicted $H_{\mathrm{V}}$ that decreases from $H_{\mathrm{V}} \sim 1.3 \mathrm{GPa}$ at $T_{\mathrm{p}} \sim 1440^{\circ} \mathrm{C}$ to $H_{\mathrm{V}} \sim 0.5 \mathrm{GPa}$ at $T_{\mathrm{p}} \sim 1730^{\circ} \mathrm{C}$ in very good agreement with the reported values $\left(H_{\mathrm{V}} \sim 1.2 \mathrm{GPa}\right.$ at $T_{\mathrm{p}} \sim 1440^{\circ} \mathrm{C}$ and $H_{\mathrm{V}} \sim 0.5 \mathrm{GPa}$ at $T_{\mathrm{p}} \sim 1730^{\circ} \mathrm{C}$, respectively). These results for Ref. 13 indicate that although increasing $T_{\mathrm{p}}$ will lead to larger graphitic crystallites, the PyC matrix will become significantly less able to resist deformation as a result of the observed growth in $L_{\mathrm{c}}$ outpacing the growth in $L_{\mathrm{a}}$. Ref. 14 considers both LD and HD PyCs, and like Ref. 13, the data included from Ref. 14 is representative data from multiple samples. Additionally, since Ref. 14 does not include an estimate of the $d_{002}$ of any of their samples, but their HD and LD PyCs that have $\rho_{\text {pyc }} \gtrsim 1.7 \mathrm{~g} / \mathrm{cm}^{3}$ agree very well with the density predictions detailed in Section S2 (Supplementary Materials), and have $L_{a} / L_{c} \lesssim 1$ characteristic of large degrees of graphitic character within the crystallites [17], $C_{44}$ for the samples that fulfill these $\rho_{\mathrm{pyc}}$ and $L_{a} / L_{c}$ requirements (i.e. all HD PyC data and two LD PyC data points) can be estimated using $C_{44} \sim 4.5 \mathrm{GPa}$ for ABAB hexagonal graphite [15].

As Fig. $3 \mathrm{~b}$ shows (error bars and dashed lines are guides to the eye and correspond to reported experimental uncertainty in the Ref. 14 data and $\pm 5 \%$ uncertainty in the Eq. $3 b$ predictions, respectively) that Eq. $3 \mathrm{~b}$ in combination with the reported values of $L_{\mathrm{a}}$ and $L_{\mathrm{c}}$ values of the HD PyCs lead to a predicted $H_{\mathrm{V}}$ that decreases from $H_{\mathrm{V}} \sim 1.2 \mathrm{GPa}$ at $T_{\mathrm{p}} \sim 1800^{\circ} \mathrm{C}$ to $H_{\mathrm{V}} \sim 0.9 \mathrm{GPa}$ at 



Figure 3: Mechanical behavior of pyrolytic carbon (PyC). (a) Illustration of the indentation technique utilized to experimentally quantify the mechanical behavior of the PyCs, i.e. via Vickers hardness $\left(H_{\mathrm{V}}\right)$, and illustration of the deformation mechanisms (at each orientation angle $\theta_{\mathrm{oa}}$ ) that govern the measured $H_{\mathrm{V}}$. (b) Scaling of $H_{\mathrm{V}}$ as a function of the pyrolyzation temperature $\left(T_{\mathrm{p}}\right)$ for the PyCs studied here, and in previous works [13, 14]. Good agreement with Eq. $3 \mathrm{~b}$ indicates that the low inter-layer shear modulus of the graphitic crystallites governs the measured $H_{\mathrm{V}}$. (c) $H_{\mathrm{V}}$ as a function of apparent density $(\rho)$ for the PyCs studied here and various other carbon materials [87], carbides, nitrides, oxides, and phosphides [34, 58, 88, 89], showing that for a structure that must be super lightweight (i.e. design parameters of $H_{\mathrm{V}}^{1 / 2} / \rho$ and $H_{\mathrm{V}}^{1 / 3} / \rho$ ) the PyCs are among the leading superhard materials. Note: hard metals are not included in the plot since they would fall in the bottom right and be covered up by the legend. 
$T_{\mathrm{p}} \sim 2000^{\circ} \mathrm{C}$ in very good agreement with the reported values $\left(H_{\mathrm{V}} \sim 1.3 \mathrm{GPa}\right.$ at $T_{\mathrm{p}} \sim 1800^{\circ} \mathrm{C}$ and $H_{\mathrm{V}} \sim 0.9 \mathrm{GPa}$ at $T_{\mathrm{p}} \sim 2000^{\circ} \mathrm{C}$, respectively). Also, as Fig. 3b shows (error bars and dashed lines are guides to the eye and again correspond to reported experimental uncertainty in the Ref. 14 data and $\pm 5 \%$ uncertainty in the Eq. 3 b predictions, respectively), Eq. $3 \mathrm{~b}$ in combination with the reported values of $L_{\mathrm{a}}$ and $L_{\mathrm{c}}$ values of the LD PyCs lead to a predicted $H_{\mathrm{V}}$ that decreases from $H_{\mathrm{V}} \sim 3.1 \mathrm{GPa}$ at $T_{\mathrm{p}} \sim 1800^{\circ} \mathrm{C}$ to $H_{\mathrm{V}} \sim 2.7 \mathrm{GPa}$ at $T_{\mathrm{p}} \sim 2000^{\circ} \mathrm{C}$ in very good agreement with the reported values $\left(H_{\mathrm{V}} \sim 3.0 \mathrm{GPa}\right.$ at $T_{\mathrm{p}} \sim 1800^{\circ} \mathrm{C}$ and $H_{\mathrm{V}} \sim 2.5 \mathrm{GPa}$ at $T_{\mathrm{p}} \sim 2000^{\circ} \mathrm{C}$, respectively) is in excellent agreement with the data and trends for both sets of samples in Refs. 13 and 14. These results for Ref. 14, like the observed trends in Ref. 13, indicate that increasing $T_{\mathrm{p}}$ will make the graphitic crystallites more graphitic in nature, and thereby diminish the hardness of the PyCs. These results demonstrate that in many lightweighting applications, for example terrestrial and air transport, where high hardness and low density are desired while the operating temperature is not expected to exceed $T_{\mathrm{p}}$, the $T_{\mathrm{p}}$ that is most likely to yield the best performing PyCs is $T_{\mathrm{p}} \sim 1000^{\circ} \mathrm{C}$ for the system studied here.

Material selection for ultralight structures requires that a candidate material, i.e. the PyCs studied here, be compared to all other materials available using two governing design parameters for hard lightweight materials using the ratios of their effective modulus and apparent density (i.e. $E_{\mathrm{eff}} / \rho, E_{\mathrm{eff}}^{1 / 2} / \rho$, and $\left.E_{\mathrm{eff}}^{1 / 3} / \rho\right)$ [90]. Since the shear deformation mechanism dominates the compliance in hard ceramic materials, which means that $E_{\text {eff }}$ is proportional to the shear modulus in these materials, while $H_{\mathrm{V}}$ scales linearly with the shear modulus in a wide variety of materials [34, 61], $H_{\mathrm{V}} / \rho, H_{\mathrm{V}}^{1 / 2} / \rho$, and $H_{\mathrm{V}}^{1 / 3} / \rho$ can be used in a similar way to compare the performance of superhard materials whose $E_{\text {eff }}$, which is normally evaluated using tensile testing that is usually not appropriate for ceramics, may not be readily available. The experimental $\rho_{\text {pyc }}$ and $H_{\mathrm{V}}$ results for the PyCs are compared to literature values for PyCs [13, 14], other carbon materials [87] and superhard carbides, nitrides, oxides, and phosphides $[34,58,88,89]$, in a $\rho$ vs. $H_{\mathrm{V}}$ Ashby-like chart (See Fig. 3c). See Table S4 (Supplementary Materials) for details. As Fig. 3c demonstrates, $H_{\mathrm{V}}$ of the PyCs studied here, on an absolute scale, is higher than the previously reported values for PyCs, graphite, and carbon fiber reinforced carbon $(\mathrm{C} / \mathrm{C})$, but is significantly lower than the $H_{\mathrm{V}}$ of other superhard materials. However, since the PyCs studied here have a low density of $\rho \lesssim 1.2$ $\mathrm{g} \mathrm{cm}^{-3}$, when the $H_{\mathrm{V}} / \rho$ design parameter, which is used for designing lightweight materials, is utilized to compare the $H_{\mathrm{V}}$ values, Fig. 3c and Table S4 (Supplementary Materials) illustrate that the performance of the PyCs pyrolyzed at $T_{\mathrm{p}}=1000^{\circ} \mathrm{C}\left(\rightarrow H_{\mathrm{V}} / \rho \sim 3.5 \mathrm{GPa} \times \mathrm{cm}^{3} \mathrm{~g}^{-1}\right)$ become comparable to the superhard AlP, AlN, TiN, and $\mathrm{ZrC}$. Additionally, when the $H_{\mathrm{V}}^{1 / 2} / \rho$ and $H_{\mathrm{V}}^{1 / 3} / \rho$ design parameters, which are used for designing lightweight materials, are utilized to analyze the performance of the PyCs, Fig. 3c and Table S4 (Supplementary Materials) illustrate that the PyCs pyrolyzed at $T_{\mathrm{p}}=1000^{\circ} \mathrm{C}$ have a specific Vickers hardness $\left(\sim 1.8 \mathrm{GPa}^{1 / 2} \mathrm{~cm}^{3} \mathrm{~g}^{-1}\right)$ that is comparable to the superhard $\mathrm{BP}$ and $\beta-\mathrm{Si}_{3} \mathrm{~N}_{4}$ and only exceeded by diamond and $\mathrm{c}-\mathrm{BN}$ in the $H_{\mathrm{V}}^{1 / 2} / \rho$ design parameter, and that their specific Vickers hardness in the $H_{\mathrm{V}}^{1 / 3} / \rho$ design parameter $\left(\sim 1.4 \mathrm{GPa}^{1 / 3} \mathrm{~cm}^{3} \mathrm{~g}^{-1}\right)$ outperform all other superhard materials while matching the performance of diamond. This means that through additional work on the optimization of the structure of the PyCs, these materials can become among the leading candidates for the design and manufacture of high hardness low density material structures, especially for lightweighting applications where they outperform the widely utilized $\mathrm{C} / \mathrm{C}$ by $>10 \times$ in $H_{\mathrm{V}} / \rho$. 


\section{Conclusions}

In summary, the structure-mechanical property relations of PyCs synthesized at pyrolyzation temperatures $\left(T_{\mathrm{p}}\right)$ ranging from $T_{\mathrm{p}}=600^{\circ} \mathrm{C}$ to $T_{\mathrm{p}}=1400^{\circ} \mathrm{C}$ were established. The XRD results indicate that the size $\left(L_{a}\right)$ and thickness $\left(L_{c}\right)$ of the graphitic crystallites in the PyCs only evolve as $T_{\mathrm{p}}$ increases from $T_{\mathrm{p}}=600^{\circ} \mathrm{C}$ to $T_{\mathrm{p}}=1000^{\circ} \mathrm{C}$, and stay about the same from $T_{\mathrm{p}}=1000^{\circ} \mathrm{C}$ to $T_{\mathrm{p}}=1400^{\circ} \mathrm{C}$, the highest $T_{\mathrm{p}}$ studied here. This indicates that at $T_{\mathrm{p}}>1000^{\circ} \mathrm{C}$, the graphitic crystallites in the PyCs become more inter-connected, i.e. via $\mathrm{sp}^{3}$ 'defects', but do not have sufficient energy to self-organize into larger crystallites, which is illustrated by a plateau in $L_{a}$ and $L_{c}$. Raman spectroscopy further supports this hypothesis, since the intensity $\left(I_{\mathrm{D}} / I_{\mathrm{G}}\right)$ and area $\left(A_{\mathrm{D}} / A_{\mathrm{G}}\right)$ ratios of the D- and G-bands increase with $T_{\mathrm{p}}$, which is normally indicative of more defects being formed, while the ratio of the half width half maximums of the D- and G-bands $\left(\gamma_{\mathrm{D}} / \gamma_{\mathrm{G}}\right)$ decreases with $T_{\mathrm{p}}$, which shows that the PyCs are moving toward becoming nanocrystalline graphite in the amorphization trajectory. Additionally, the results of FTIR spectroscopy also support this idea by showing that there is noticeable chemical evolution of the PyCs from $T_{\mathrm{p}}=600^{\circ} \mathrm{C}$ to $T_{\mathrm{p}}=1000^{\circ} \mathrm{C}$, while the spectra do not change significantly from $T_{\mathrm{p}}=1000^{\circ} \mathrm{C}$ to $T_{\mathrm{p}}=1400^{\circ} \mathrm{C}$. Since the $C_{44}$ $\left(\rightarrow C_{44} \sim 0.3-5 \mathrm{GPa}\right)$ inter-layer shear elastic constant for graphitic materials is orders of magnitude smaller than the in-plane $C_{11}\left(\rightarrow C_{11} \sim 1 \mathrm{TPa}\right)$ and out-of-plane $C_{33}\left(\rightarrow C_{33} \sim 30-40\right.$ GPa) extension elastic constants, the model developed shows that $C_{44}$ by far dominates the measured $H_{\mathrm{V}}$ of the PyCs. Additionally, modeling indicates that the evolution of $L_{a} / L_{c}$ and inter-layer separation $\left(d_{002}\right)$ explains the observed non-monotonic scaling of Vickers hardness $\left(H_{\mathrm{V}}\right)$ with $T_{\mathrm{p}}$, where smaller $d_{002}$ and larger $L_{a} / L_{c}$ correspond to enhanced mechanical performance. These results indicate that although increasing $T_{\mathrm{p}}$ can lead to crystallites that are more graphitic in nature (i.e. $d_{002}$ close to the ideal $d_{002} \sim 0.3357 \mathrm{~nm}$ for graphite), which increases their $C_{44}$, this higher $T_{\mathrm{p}}$ will also lead to much smaller aspect ratio crystallites (i.e. $L_{a} / L_{c}$ decreases), which makes them more sensitive to inter-layer shear deformation. This means that although pyrolysis at higher temperatures can lead to more graphite-like PyCs, their mechanical performance will be diminished. Such an insight helps dispel the confusion in the literature that surrounds why some PyCs get softer as $T_{\mathrm{p}}$ increases, while others remain superhard, and this is directly the result of the evolution of their average $L_{a}, L_{c}$, and $d_{002}$. Since the three-dimensional shape of the pores enclosed by the crystallites and the crystallite curvature/orientation are important inputs for mechanical modeling, but were not available for this study since they cannot be quantified using traditional electron microscopy approaches that yield two-dimensional projections, further work via electron tomography (for three-dimensional crystallite visualization) [91], small angle X-ray scattering (for large sampled volume quantitative analysis) [92, 93], and selected area electron diffraction (for crystallite texture/preferential alignment quantification) $[14,44,45]$ is required and could enable improved mechanical property predictions for PyCs [60]. Comparison of the $H_{\mathrm{V}}$ results of PyCs using their apparent density $(\rho)$ and the design parameters for lightweight $\left(H_{\mathrm{V}} / \rho\right)$ and super lightweight $\left(H_{\mathrm{V}}^{1 / 2} / \rho\right.$ and $\left.H_{\mathrm{V}}^{1 / 3} / \rho\right)$ material design parameters shows that the performance of the PyCs studied here is average for superhard materials using the $H_{\mathrm{V}} / \rho$ design parameter, and among the best performing superhard materials when the $H_{\mathrm{V}}^{1 / 2} / \rho$ and $H_{\mathrm{V}}^{1 / 3} / \rho$ design parameter are used. Also, since nanoindentation is commonly applied to estimate the indentation hardness and reduced elastic modulus (via the unload curve) of nanostructured materials, but these results are not cur- 
rently directly compatible with hardness estimates resulting from the Vickers approach, further work that quantifies how the tip geometry and indentation testing conditions modify the estimated hardness, bulk modulus, and elastic modulus could be pursued. Since the PyCs studied here can be manufactured at meter-scale using scalable polymer derived ceramics processing, exhibit thermal stability at temperatures $>1400^{\circ} \mathrm{C}$, but their specific Vickers hardness is not yet comparable to or better than the state-of-the-art superhard materials (i.e. diamond and $\mathrm{c}-\mathrm{BN}$ ), additional work is required to further improve the mechanical performance of the PyCs through reinforcement with nano-fibers or wires, such as carbon nanotubes (CNTs), that could potentially also enhance the fracture toughness of these materials. Such work can lead to next-generation super lightweight material architectures with specific hardness that rivals or exceeds that of diamond.

\section{Acknowledgements}

I.Y.S. was supported by the Department of Defense (DoD) through the National Defense Science \& Engineering Graduate Fellowship (NDSEG) Program. A.J.C. and N.M.-M. were supported by the CMSE Research Experience for Undergraduates Program, as part of the MRSEC Program of the National Science Foundation under grant number DMR-08-19762, and the MIT Materials Processing Center. This work was partially supported by Airbus Group, Boeing, Embraer, Lockheed Martin, Saab AB, ANSYS, Hexcel, and TohoTenax through MIT's Nano-Engineered Composite aerospace STructures (NECST) Consortium. The authors thank T. McClure, C. Settens, and D. Bono for helpful discussions, and the members of necstlab at MIT for technical support and advice. This work made use of the MRSEC Shared Experimental Facilities at MIT, supported by the National Science Foundation under award number DMR-08-19762, and utilized the core facilities at the Institute for Soldier Nanotechnologies at MIT, supported in part by the U.S. Army Research Office under contracts W911NF-07-D-0004 and W911NF-13-D-0001.

\section{References}

[1] J. Bauer, A. Schroer, R. Schwaiger, O. Kraft, Approaching Theoretical Strength in Glassy Carbon Nanolattices, Nat. Mater. 15 (2016) 438-443. doi : $10.1038 /$ nmat4561.

[2] X. Li, H. Gao, Mechanical Metamaterials: Smaller and Stronger, Nat. Mater. 15 (2016) 373-374. doi:10. $1038 /$ nmat 4591.

[3] G. Pacchioni, Mechanical Metamaterials: The Strength Awakens, Nat. Rev. Mater. 1 (2016) 16012. doi: 10.1038/natrevmats. 2016.12.

[4] A. J. Jacobsen, S. Mahoney, W. B. Carter, S. Nutt, Vitreous Carbon Micro-Lattice Structures, Carbon 49 (2011) 1025 - 1032. doi:10.1016/j.carbon.2010.10.059.

[5] D. B. Burckel, C. M. Washburn, A. K. Raub, S. R. J. Brueck, D. R. Wheeler, S. M. Brozik, R. Polsky, Lithographically Defined Porous Carbon Electrodes, Small 5 (2009) 2792-2796. doi : 10 . 1002/sml1 . 200901084.

[6] J.-H. Lee, J. P. Singer, E. L. Thomas, Micro-/Nanostructured Mechanical Metamaterials, Adv. Mater. 24 (2012) 4782-4810. doi:10.1002/adma.201201644. 
[7] S. Jiang, T. Shi, X. Zhan, S. Xi, H. Long, B. Gong, J. Li, S. Cheng, Y. Huang, Z. Tang, Scalable Fabrication of Carbon-Based MEMS/NEMS and Their Applications: a Review, J. Micromech. Microeng. 25 (2015) 113001. doi: 10.1088/0960-1317/25/11/113001.

[8] O. J. A. Schueller, S. T. Brittain, C. Marzolin, G. M. Whitesides, Fabrication and Characterization of Glassy Carbon MEMS, Chem. Mater. 9 (1997) 1399-1406. doi:10.1021/cm960639v.

[9] O. J. A. Schueller, S. T. Brittain, G. M. Whitesides, Fabrication of Glassy Carbon Microstructures by Pyrolysis of Microfabricated Polymeric Precursors, Adv. Mater. 9 (1997) 477-480. doi : 10. 1002/adma. 19970090604.

[10] O. J. Schueller, S. T. Brittain, G. M. Whitesides, Fabrication of Glassy Carbon Microstructures by Soft Lithography, Sens. Actuators, A 72 (1999) 125 - 139. doi : 10.1016/S0924-4247 (98)00218-0.

[11] M. Šupová, J. Svítilová, Z. Chlup, M. Černý, Z. Weishauptová, T. Suchý, V. Machovič, Z. Sucharda, M. Žaloudková, Relation Between Mechanical Properties and Pyrolysis Temperature of Phenol Formaldehyde Resin for Gas Separation Membranes, Ceram.-Silik. 56 (2012) 40-49.

[12] Z. Laušević, S. Marinković, Mechanical Properties and Chemistry of Carbonization of Phenol Formaldehyde Resin, Carbon 24 (1986) 575 - 580. doi : 10.1016/0008-6223(86) 90148-X.

[13] S. Yajima, T. Hirai, T. Hayase, Microhardness of Pyrolytic Graphite and Siliconated Pyrolytic Graphite, Tanso No. 69 (1972) 41. doi:10.7209/tanso.1972.41.

[14] H. Zhang, E. López-Honorato, P. Xiao, Fluidized Bed Chemical Vapor Deposition of Pyrolytic Carbon-III. Relationship Between Microstructure and Mechanical Properties, Carbon 91 (2015) 346 - 357. doi : 10.1016/ j. carbon.2015.05.009.

[15] G. Savini, Y. Dappe, S. Öberg, J.-C. Charlier, M. Katsnelson, A. Fasolino, Bending Modes, Elastic Constants and Mechanical Stability of Graphitic Systems, Carbon 49 (2011) 62 - 69. doi:10.1016/j.carbon. 2010. 08.042 .

[16] X. Zhang, C. Neumann, P. Angelova, A. Beyer, A. Gölzhäuser, Tailoring the Mechanics of Ultrathin Carbon Nanomembranes by Molecular Design, Langmuir 30 (2014) 8221-8227. doi : 10.1021/la501961d.

[17] R. E. Franklin, Crystallite Growth in Graphitizing and Non-Graphitizing Carbons, Proc. R. Soc. London, Ser. A 209 (1951) 196-218. doi:10.1098/rspa.1951.0197.

[18] A. C. Forse, C. Merlet, P. K. Allan, E. K. Humphreys, J. M. Griffin, M. Aslan, M. Zeiger, V. Presser, Y. Gogotsi, C. P. Grey, New Insights into the Structure of Nanoporous Carbons from NMR, Raman, and Pair Distribution Function Analysis, Chem. Mater. 27 (2015) 6848-6857. doi:10.1021/acs . chemmater.5b03216.

[19] J. Zhang, J. Shi, Y. Zhao, Q. Guo, L. Liu, Z. Feng, Z. Fan, Structural Changes in Four Different Precursors with Heat Treatment at High Temperature and Resin Carbon Structural Model, J. Mater. Sci. 47 (2012) 5891-5899. doi: 10.1007/s10853-012-6492-1.

[20] M. B. Vázquez-Santos, E. Geissler, K. László, J.-N. Rouzaud, A. Martínez-Alonso, J. M. D. Tascón, Graphitization of Highly Porous Carbons Derived from Poly(p-Phenylene Benzobisoxazole), Carbon 50 (2012) 2929 2940. doi:10.1016/j. carbon.2012.02.062.

[21] C. Hu, S. Sedghi, A. Silvestre-Albero, G. G. Andersson, A. Sharma, P. Pendleton, F. Rodrguez-Reinoso, K. Kaneko, M. J. Biggs, Raman Spectroscopy Study of the Transformation of the Carbonaceous Skeleton of a Polymer-Based Nanoporous Carbon Along the Thermal Annealing Pathway, Carbon 85 (2015) 147 - 158. doi:10.1016/j.carbon.2014.12.098.

[22] K. Faber, F. Badaczewski, M. Oschatz, G. Mondin, W. Nickel, S. Kaskel, B. M. Smarsly, In-Depth Investigation of the Carbon Microstructure of Silicon Carbide-Derived Carbons by Wide-Angle X-Ray Scattering, J. Phys. Chem. C 118 (2014) 15705-15715. doi:10.1021/jp502832x.

[23] N. Iwashita, C. R. Park, H. Fujimoto, M. Shiraishi, M. Inagaki, Specification for a Standard Procedure of X-Ray Diffraction Measurements on Carbon Materials, Carbon 42 (2004) 701 - 714. doi: 10 .1016/j . carbon. 2004. 02.008

[24] G. A. Zickler, B. Smarsly, N. Gierlinger, H. Peterlik, O. Paris, A Reconsideration of the Relationship Between the Crystallite Size La of Carbons Determined by X-Ray Diffraction and Raman Spectroscopy , Carbon 44 (2006) 3239 - 3246. doi :10.1016/j. carbon. 2006.06.029.

[25] H. Badenhorst, Microstructure of Natural Graphite Flakes Revealed by Oxidation: Limitations of XRD and Raman Techniques for Crystallinity Estimates, Carbon 66 (2014) 674 - 690. doi :10.1016/j . carbon . 2013. 09.065 . 
[26] C. D. Latham, M. I. Heggie, M. Alatalo, S. Öberg, P. R. Briddon, The Contribution Made by Lattice Vacancies to the Wigner Effect in Radiation-Damaged Graphite, J. Phys.: Condens. Matter 25 (2013) 135403. doi: 10.1088/0953-8984/25/13/135403.

[27] G. Lopez-Polin, C. Gomez-Navarro, V. Parente, F. Guinea, M. I. Katsnelson, F. Perez-Murano, J. GomezHerrero, Increasing the Elastic Modulus of Graphene by Controlled Defect Creation, Nat. Phys. 11 (2015) 26-31. doi:10.1038/nphys3183.

[28] A. Gamboa, B. Farbos, P. Aurel, G. L. Vignoles, J.-M. Leyssale, Mechanism of Strength Reduction Along the Graphenization Pathway, Sci. Adv. 1 (2015) e1501009. doi:10.1126/sciadv.1501009.

[29] B. Farbos, J.-P. D. Costa, G. Vignoles, J.-M. Leyssale, Nanoscale Elasticity of Highly Anisotropic Pyrocarbons, Carbon 94 (2015) 285 - 294. doi:10.1016/j. carbon.2015.06.060.

[30] A. Shekhawat, R. O. Ritchie, Toughness and Strength of Nanocrystalline Graphene, Nat. Commun. 7 (2016) 10546. doi:10.1038/ncomms 10546.

[31] A. Zandiatashbar, G.-H. Lee, S. J. An, S. Lee, N. Mathew, M. Terrones, T. Hayashi, C. R. Picu, J. Hone, N. Koratkar, Effect of Defects on the Intrinsic Strength and Stiffness of Graphene, Nat. Commun. 5 (2014) 3186. doi:10.1038/ncomms4186.

[32] C. A. Schuh, Nanoindentation Studies of Materials, Mater. Today 9 (2006) 32 - 40. doi:10.1016/ S1369-7021 (06)71495-X.

[33] U. Ramamurty, J.-i. Jang, Nanoindentation for Probing the Mechanical Behavior of Molecular Crystals-a Review of the Technique and How to Use It, CrystEngComm 16 (2014) 12-23. doi : 10.1039/C3CE41266K.

[34] X.-Q. Chen, H. Niu, D. Li, Y. Li, Modeling Hardness of Polycrystalline Materials and Bulk Metallic Glasses, Intermetallics 19 (2011) 1275 - 1281. doi:10.1016/j.intermet.2011.03.026.

[35] R. Dettori, E. Cadelano, L. Colombo, Elastic Fields and Moduli in Defected Graphene, J. Phys.: Condens. Matter 24 (2012) 104020. doi:10.1088/0953-8984/24/10/104020.

[36] J. Wang, T. Kemper, T. Liang, S. B. Sinnott, Predicted Mechanical Properties of a Coiled Carbon Nanotube, Carbon 50 (2012) 968 - 976. doi:10.1016/j. carbon.2011.09.060.

[37] J.-W. Jiang, J.-S. Wang, B. Li, Young's Modulus of Graphene: A Molecular Dynamics Study, Phys. Rev. B: Condens. Matter Mater. Phys. 80 (2009) 113405. doi :10.1103/PhysRevB .80.113405.

[38] H. Zhao, K. Min, N. R. Aluru, Size and Chirality Dependent Elastic Properties of Graphene Nanoribbons Under Uniaxial Tension, Nano Lett. 9 (2009) 3012-3015. doi : 10.1021/n1901448z.

[39] S. Bera, A. Arnold, F. Evers, R. Narayanan, P. Wölfle, Elastic Properties of Graphene Flakes: Boundary Effects and Lattice Vibrations, Phys. Rev. B: Condens. Matter Mater. Phys. 82 (2010) 195445. doi: 10.1103/PhysRevB.82.195445.

[40] P. Linkov, M. Artemyev, A. E. Efimov, I. Nabiev, Comparative advantages and limitations of the basic metrology methods applied to the characterization of nanomaterials, Nanoscale 5 (2013) 8781-8798. doi:10.1039/ C3NR02372A.

[41] B. Zhang, D. S. Su, Transmission Electron Microscopy and the Science of Carbon Nanomaterials, Small 10 (2014) 222-229. doi:10.1002/smll.201301303.

[42] D. S. Su, B. Zhang, R. Schlögl, Electron Microscopy of Solid Catalysts-Transforming from a Challenge to a Toolbox, Chem. Rev. 115 (2015) 2818-2882. doi:10.1021/cr500084c.

[43] W. Zhang, W. T. Zheng, Transmission electron microscopy finds plenty of room on the surface, Phys. Chem. Chem. Phys. 17 (2015) 14461-14469. doi:10.1039/C5CP01705J.

[44] E. López-Honorato, P. Meadows, P. Xiao, Fluidized Bed Chemical Vapor Deposition of Pyrolytic Carbon - I. Effect of Deposition Conditions on Microstructure, Carbon 47 (2009) 396 - 410. doi : 10.1016/j . carbon. 2008.10.023.

[45] P. Meadows, E. López-Honorato, P. Xiao, Fluidized Bed Chemical Vapor Deposition of Pyrolytic Carbon - II. Effect of Deposition Conditions on Anisotropy, Carbon 47 (2009) 251 - 262. doi : 10.1016/j . carbon . 2008. 10.003.

[46] Z.-L. Zhang, R. Brydson, Z. Aslam, S. Reddy, A. Brown, A. Westwood, B. Rand, Investigating the structure of non-graphitising carbons using electron energy loss spectroscopy in the transmission electron microscope , Carbon 49 (2011) 5049-5063. doi: 10.1016/j. carbon. 2011.07.023.

[47] C. Hu, A. C. Liu, M. Weyland, S. H. Madani, P. Pendleton, F. Rodríguez-Reinoso, K. Kaneko, M. J. Biggs, A 
multi-method study of the transformation of the carbonaceous skeleton of a polymer-based nanoporous carbon along the activation pathway, Carbon 85 (2015) 119 - 134. doi : 10.1016/j . carbon.2014.12.051.

[48] I. Y. Stein, H. M. Vincent, S. A. Steiner, E. Colombini, B. L. Wardle, Processing and Mechanical Property Characterization of Aligned Carbon Nanotube Carbon Matrix Nanocomposites, in: 54th AIAa Structures, Structural Dynamics, and Materials (SDM) Conference, Boston, MA, 2013. doi : 10.2514/6.2013-1583.

[49] I. Y. Stein, Synthesis and Characterization of Next-Generation Multifunctional Material Architectures: Aligned Carbon Nanotube Carbon Matrix Nanocomposites, Master's thesis, Massachusetts Institute of Technology (2013).

URL http: //hdl . handle.net/1721.1/81728

[50] I. Y. Stein, B. L. Wardle, Morphology and Processing of Aligned Carbon Nanotube Carbon Matrix Nanocomposites, Carbon 68 (2014) 807 -813. doi : 10.1016/j. carbon.2013.12.001.

[51] M. S. Nyathi, C. B. Clifford, H. H. Schobert, Characterization of Graphitic Materials Prepared from Different Rank Pennsylvania Anthracites, Fuel 114 (2013) 244 - 250. doi:10.1016/j.fuel.2012.04.003.

[52] M. W. Smith, I. Dallmeyer, T. J. Johnson, C. S. Brauer, J.-S. McEwen, J. F. Espinal, M. Garcia-Perez, Structural Analysis of Char by Raman Spectroscopy: Improving Band Assignments Through Computational Calculations from First Principles, Carbon 100 (2016) 678 - 692. doi:10.1016/j . carbon.2016.01.031.

[53] V. Tsaneva, W. Kwapinski, X. Teng, B. Glowacki, Assessment of the Structural Evolution of Carbons from Microwave Plasma Natural Gas Reforming and Biomass Pyrolysis Using Raman Spectroscopy, Carbon 80 (2014) 617 - 628. doi:10.1016/j . carbon.2014.09.005.

[54] A. C. Ferrari, J. Robertson, Interpretation of Raman Spectra of Disordered and Amorphous Carbon, Phys. Rev. B: Condens. Matter Mater. Phys. 61 (2000) 14095-14107. doi:10.1103/PhysRevB.61.14095.

[55] P. Mallet-Ladeira, P. Puech, P. Weisbecker, G. L. Vignoles, M. Monthioux, Behavior of Raman D Band for Pyrocarbons with Crystallite Size in the 2-5 nm Range, Appl. Phys. A 114 (2014) 759-763. doi:10.1007/ s00339-013-7671-x.

[56] P. Mallet-Ladeira, P. Puech, C. Toulouse, M. Cazayous, N. Ratel-Ramond, P. Weisbecker, G. L. Vignoles, M. Monthioux, A Raman Study to Obtain Crystallite Size of Carbon Materials: A Better Alternative to the Tuinstra-Koenig Law, Carbon 80 (2014) 629 - 639. doi:10.1016/j . carbon.2014.09.006.

[57] ASTM C1327-08. Standard Test Method for Vickers Indentation Hardness of Advanced Ceramics, ASTM International.

[58] B. D. Fulcher, X. Y. Cui, B. Delley, C. Stampfl, Hardness Analysis of Cubic Metal Mononitrides from First Principles, Phys. Rev. B: Condens. Matter Mater. Phys. 85 (2012) 184106. doi:10.1103/PhysRevB. 85. 184106.

[59] L. Zhou, D. Holec, P. H. Mayrhofer, First-principles study of elastic properties of cubic $\mathrm{Cr}_{1-x} \mathrm{Al}_{x} \mathrm{~N}$ alloys, J. Appl. Phys. 113 (4) (2013) 043511. doi:10.1063/1.4789378.

[60] M. P. Moody, A. V. Ceguerra, A. J. Breen, X. Y. Cui, B. Gault, L. T. Stephenson, R. K. W. Marceau, R. C. Powles, S. P. Ringer, Atomically resolved tomography to directly inform simulations for structure-property relationships, Nat. Commun. 5 (2014) 5501. doi:10.1038/ncomms6501.

[61] Y. Gogotsi, S. Welz, D. A. Ersoy, M. J. McNallan, Conversion of Silicon Carbide to Crystalline DiamondStructured Carbon at Ambient Pressure, Nature 411 (2001) 283-287. doi : 10.1038/35077031.

[62] X. Li, K. Li, H. Li, J. Wei, C. Wang, Microstructures and Mechanical Properties of Carbon/carbon Composites Reinforced with Carbon Nanofibers/nanotubes Produced in Situ, Carbon 45 (2007) 1662 - 1668. doi: 10. 1016/j.carbon.2007.03.042.

[63] Z. Li, C. Lu, Z. Xia, Y. Zhou, Z. Luo, X-Ray Diffraction Patterns of Graphite and Turbostratic Carbon, Carbon 45 (2007) 1686 - 1695. doi:10.1016/j. carbon.2007.03.038.

[64] J. Rautavuori, P. Törmälä, Preparation of Bulky Glassy Carbon Bodies from Phenolformaldehyde Resin, J. Mater. Sci. 14 (1979) 2020-2022. doi :10.1007/BF00551046.

[65] S. Sharma, R. Kamath, M. Madou, Porous Glassy Carbon Formed by Rapid Pyrolysis of Phenol-Formaldehyde Resins and Its Performance As Electrode Material for Electrochemical Double Layer Capacitors, J. Anal. Appl. Pyrol. 108 (2014) 12 - 18. doi:10.1016/j.jaap.2014.05.025.

[66] C. L. Burket, R. Rajagopalan, H. C. Foley, Overcoming the Barrier to Graphitization in a Polymer-Derived Nanoporous Carbon, Carbon 46 (2008) 501 - 510. doi : 10.1016/j . carbon.2007.12.016. 
[67] A. C. Ferrari, D. M. Basko, Raman Spectroscopy As a Versatile Tool for Studying the Properties of Graphene, Nat. Nanotechnol. 8 (2013) 235-246. doi : 10.1038/nnano. 2013.46.

[68] M. S. Dresselhaus, A. Jorio, M. Hofmann, G. Dresselhaus, R. Saito, Perspectives on Carbon Nanotubes and Graphene Raman Spectroscopy, Nano Lett. 10 (2010) 751-758. doi :10.1021/n1904286r.

[69] A. V. Krasheninnikov, K. Nordlund, Ion and Electron Irradiation-Induced Effects in Nanostructured Materials, J. Appl. Phys. 107 (2010) 071301. doi : 10.1063/1.3318261.

[70] A. C. Ferrari, J. C. Meyer, V. Scardaci, C. Casiraghi, M. Lazzeri, F. Mauri, S. Piscanec, D. Jiang, K. S. Novoselov, S. Roth, A. K. Geim, Raman Spectrum of Graphene and Graphene Layers, Phys. Rev. Lett. 97 (2006) 187401. doi:10.1103/PhysRevLett.97.187401.

[71] C. A. Amadei, I. Y. Stein, G. J. Silverberg, B. L. Wardle, C. D. Vecitis, Fabrication and Chemomechanical Tuning of Graphene Oxide Nanoscrolls, Nanoscale 8 (2016) 6783. doi:10.1039/C5NR07983G.

[72] F. Tuinstra, J. L. Koenig, Raman Spectrum of Graphite, J. Chem. Phys. 53 (1970) 1126-1130. doi:10.1063/ 1.1674108.

[73] L. G. Cançado, K. Takai, T. Enoki, M. Endo, Y. A. Kim, H. Mizusaki, A. Jorio, L. N. Coelho, R. M. aes Paniago, M. A. Pimenta, General Equation for the Determination of the Crystallite Size $L_{\mathrm{a}}$ of Nanographite by Raman Spectroscopy, Appl. Phys. Lett. 88 (2006) 163106. doi:10.1063/1.2196057.

[74] L. G. Cançado, A. Jorio, E. H. M. Ferreira, F. Stavale, C. A. Achete, R. B. Capaz, M. V. O. Moutinho, A. Lombardo, T. S. Kulmala, A. C. Ferrari, Quantifying Defects in Graphene Via Raman Spectroscopy at Different Excitation Energies, Nano Lett. 11 (2011) 3190-3196. doi :10.1021/n1201432g.

[75] M. S. Shafeeyan, W. M. A. W. Daud, A. Houshmand, A. Shamiri, A Review on Surface Modification of Activated Carbon for Carbon Dioxide Adsorption, J. Anal. Appl. Pyrol. 89 (2010) 143 - 151. doi:10.1016/j. jaap. 2010.07.006.

[76] B. Strzemiecka, A. Voelkel, J. Ziba-Palus, T. Lachowicz, Assessment of the Chemical Changes During Storage of Phenol-Formaldehyde Resins Pyrolysis Gas Chromatography Mass Spectrometry, Inverse Gas Chromatography and Fourier Transform Infra Red Methods, J. Chromatogr. A 1359 (2014) 255 - 261. doi: 10.1016/j.chroma.2014.07.045.

[77] X. Lu, L. Li, B. Song, K. sik Moon, N. Hu, G. Liao, T. Shi, C. Wong, Mechanistic Investigation of the Graphene Functionalization Using P-Phenylenediamine and Its Application for Supercapacitors, Nano Energy 17 (2015) 160 - 170. doi:10.1016/j.nanoen.2015.08.011.

[78] S. Biniak, A. Światkowski, M. Pakuła, M. Sankowska, K. Kuśmierek, G. Trykowski, Cyclic Voltammetric and FTIR Studies of Powdered Carbon Electrodes in the Electrosorption of 4-Chlorophenols from Aqueous Electrolytes, Carbon 51 (2013) 301 - 312. doi:10.1016/j . carbon.2012.08.057.

[79] A. Bosak, M. Krisch, M. Mohr, J. Maultzsch, C. Thomsen, Elasticity of Single-Crystalline Graphite: Inelastic X-Ray Scattering Study, Phys. Rev. B: Condens. Matter Mater. Phys. 75 (2007) 153408. doi: 10.1103/PhysRevB.75.153408.

[80] P. H. Tan, W. P. Han, W. J. Zhao, Z. H. Wu, K. Chang, H. Wang, Y. F. Wang, N. Bonini, N. Marzari, N. Pugno, G. Savini, A. Lombardo, A. C. Ferrari, The Shear Mode of Multilayer Graphene, Nat. Mater. 11 (2012) 294-300. doi: $10.1038 /$ nmat3245.

[81] X. Chen, C. Yi, C. Ke, Bending Stiffness and Interlayer Shear Modulus of Few-Layer Graphene, Appl. Phys. Lett. 106 (2015) 101907. doi:10.1063/1.4915075.

[82] C. Tang, Y. Zhang, W. Guo, C. Chen, Thermally Activated Interlayer Bonding in Multiwalled Carbon Nanotubes, J. Phys. Chem. C 114 (2010) 18091-18095. doi:10.1021/jp106444n.

[83] M. Daly, C. Cao, H. Sun, Y. Sun, T. Filleter, C. V. Singh, Interfacial Shear Strength of Multilayer Graphene Oxide Films, ACS Nano 10 (2016) 1939-1947. doi:10.1021/acsnano.5b05771.

[84] X. Zhang, W. P. Han, J. B. Wu, S. Milana, Y. Lu, Q. Q. Li, A. C. Ferrari, P. H. Tan, Raman Spectroscopy of Shear and Layer Breathing Modes in Multilayer $\mathrm{MoS}_{2}$, Phys. Rev. B: Condens. Matter Mater. Phys. 87 (2013) 115413. doi:10.1103/PhysRevB.87.115413.

[85] C. Cong, T. Yu, Enhanced Ultra-Low-Frequency Interlayer Shear Modes in Folded Graphene Layers, Nat. Commun. 5 (2014) 4709. doi : 10.1038/ncomms5709.

[86] E. Lorchat, G. Froehlicher, S. Berciaud, Splitting of Interlayer Shear Modes and Photon Energy Dependent Anisotropic Raman Response in N-Layer ReSe2 and ReS2, ACS Nano 10 (2016) 2752-2760. doi:10.1021/ 
acsnano. 5 b07844.

[87] T. Oku, A. Kurumada, Y. Imamura, M. Ishihara, Effects of Ion Irradiation on the Hardness Properties of Graphites and C/C Composites by Indentation Tests, J. Nucl. Mater. 381 (2008) 92 - 97. doi:10.1016/j . jnucmat.2008.07.026.

[88] D. M. Teter, Computational Alchemy: The Search for New Superhard Materials, MRS Bull. 23 (1998) $22-27$. doi: 10.1557/S0883769400031420.

[89] R. Andrievski, Superhard Materials Based on Nanostructured High-Melting Point Compounds: Achievements and Perspectives, Int. J. Refract. Met. Hard Mater. 19 (2001) 447 - 452. doi:10.1016/S0263-4368(01) 00023-3.

[90] M. F. Ashby, Materials Selection in Mechanical Design, 4th Edition, Butterworth-Heinemann, 2010.

[91] B. Natarajan, N. Lachman, T. Lam, D. Jacobs, C. Long, M. Zhao, B. L. Wardle, R. Sharma, J. A. Liddle, The Evolution of Carbon Nanotube Network Structure in Unidirectional Nanocomposites Resolved by Quantitative Electron Tomography, ACS Nano 9 (2015) 6050-6058. doi : 10.1021/acsnano.5b01044.

[92] O. Paris, D. Loidl, H. Peterlik, Texture of PAN- and pitch-based carbon fibers, Carbon 40 (4) (2002) 551 - 555. doi:10.1016/S0008-6223(01)00139-7.

[93] M. Sopronyi, F. Sima, C. Vaulot, L. Delmotte, A. Bahouka, C. Matei Ghimbeu, Direct synthesis of graphitic mesoporous carbon from green phenolic resins exposed to subsequent UV and IR laser irradiations, Sci. Rep. 6 (2016) 39617. doi:10.1038/srep39617. 
